\title{
Socioeconomic determinants of excess weight and obesity among Indigenous women: findings from the First National Survey of Indigenous People's Health and Nutrition in Brazil
}

\author{
Carlos EA Coimbra, Jr. ${ }^{1, *}$ (D), Felipe G Tavares ${ }^{2}$, Aline A Ferreira ${ }^{3}$, James R Welch¹, \\ Bernardo L Horta ${ }^{4}$, Andrey M Cardoso' and Ricardo Ventura Santos ${ }^{1,5}$ \\ 'Escola Nacional de Saúde Pública, Fundação Oswaldo Cruz, Rio de Janeiro, RJ 21041-210, Brazil: ${ }^{2}$ Escola de \\ Enfermagem Aurora de Afonso Costa, Universidade Federal Fluminense, Niterói, RJ 24020-091, Brazil: ${ }^{3}$ Instituto de \\ Nutrição Josué de Castro, Universidade Federal do Rio de Janeiro, Rio de Janeiro, RJ 21941 -902, Brazil: ${ }^{4}$ Programa \\ de Pós-Graduação em Epidemiologia, Universidade Federal de Pelotas, Pelotas, RS 96001-970, Brazil: \\ ${ }_{5}^{5}$ Departamento de Antropologia, Museu Nacional, Universidade Federal do Rio de Janeiro, Rio de Janeiro, \\ RJ 20940-040, Brazil
}

Submitted 13 October 2019: Final revision received 13 January 2020: Accepted 26 February 2020: First published online 1 June 2020

\begin{abstract}
Objective: This article assesses the nutritional status of Indigenous women from 14 to 49 years of age in Brazil.

Design: Sample size was calculated for each region considering a prevalence of $50 \%$ for all disease outcomes, a relative error of $5 \%$ and a CI of $95 \%$. In the initial data analysis, the prevalence of excess weight and obesity was calculated according to independent variables. Multivariate multilevel hierarchical analyses were conducted based on a theoretical model of two ranked blocks.

Setting: The 2010 Indigenous population in Brazil was 896 000, with approximately 300 Indigenous ethnic groups, making Brazil one of the most ethnically diverse countries in the Americas and the world.

Participants: Of the total target sample of 6722 women evaluated by the National Survey, thirty did not participate, 939 were not eligible for analyses due to pregnancy or unknown pregnancy status, and thirty-nine were excluded due to missing anthropometric data.

Results: The evaluation of nutritional status was completed for 5714 non-pregnant women (99.3\% of eligible participants for this outcome). High prevalence rates were encountered for both excess weight (46.2\%) and obesity (15.8\%) among the sampled women. In the multivariate analyses, higher socioeconomic indicators, market-integrated living conditions and less reliance on local food production, as well as increased age and parity were associated with excess weight and obesity. Conclusion: Results point to distinct patterns of associations between socioeconomic indicators and the occurrence of excess weight and obesity among Indigenous women, which have potentially significant implications from a public policy perspective for Indigenous peoples in Brazil.
\end{abstract}

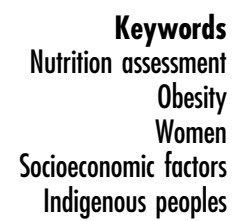

Globally, questions about excess weight in human populations are among the most urgent of contemporary public health priorities. Accelerated increases in overweight and obesity prevalence during recent decades are demonstrated for diverse countries worldwide ${ }^{(1-3)}$. Overweight and obesity are implicated as risk factors for a set of linked chronic non-communicable diseases, such as CVD, diabetes mellitus and some kinds of cancer ${ }^{(4,5)}$.
According to Stevens, in 2008 approximately one in nine adults worldwide was obese, and at least one in five women in 117 countries was obese ${ }^{(3)}$. In some low- and medium-income countries, the nutritional transition has progressed at an even more accelerated rate than has been observed globally due to recent socioeconomic and environmental changes that contribute to rural-urban migration and conversion, substitution of traditional diets, and 
increased physical inactivity, among other factors associated with excess weight ${ }^{(6,7)}$. In Brazil, nutrition transition has been observed since the mid-1970s along with highly unequal distributions of obesity and chronic diseases following income, education, race or ethnicity and other sociodemographic indicators ${ }^{(8,9)}$. Recent surveys of physical activity in Brazil showed relatively low proportions of male and female adults considered to be physically active $^{(10-12)}$.

Until recently, few studies compared the health of Indigenous populations internationally ${ }^{(13)}$, although numerous investigations showed that exposure to social and environmental factors associated with nutrition transition, especially obesity, is a common occurrence. For example, Story reported that in North America 'obesity has become a major health problem in American Indians only in the past 1-2 generations and is believed to be associated with the relative abundance of high-fat foods and the rapid change from active to sedentary lifestyles ${ }^{\prime(14)}$ (p. 747S). In other countries and regions with large Indigenous populations, such as Canada, Australia, the Pacific Islands and Greenland, obesity and associated metabolic and cardiovascular diseases also stand out as important public health issues ${ }^{(15-18)}$. Although epidemiological information for Latin America is more dispersed, recent analyses indicated that obesity among Indigenous peoples is increasing rapidly in association with cardiovascular and metabolic diseases ${ }^{(19-21)}$.

The appearance and rapid increase in obesity, diabetes mellitus and arterial hypertension prevalence among Indigenous peoples in Brazil has been observed since the 1970 s and 1980s, especially in the Amazon region ${ }^{(22-24)}$. More recently, case studies have documented elevated prevalence of excess weight in diverse Indigenous ethnic groups located throughout the country ${ }^{(25-30)}$. At the same time, this population continues to suffer from a high prevalence of chronic undernutrition and of preventable infectious and parasitic diseases affecting mostly children ${ }^{(31-33)}$.

The epidemiology of excess weight and obesity in Brazil is the focus of growing attention, but no previous study has addressed the subject for Indigenous peoples nationally. The First National Survey of Indigenous People's Health and Nutrition in Brazil (henceforth 'National Survey'), conducted in 2008-9, was the first study to evaluate a nationwide representative sample of Indigenous peoples throughout the country. It is the most comprehensive investigation yet conducted on the nutritional situation of Indigenous adult women in Brazil, and one of the most extensive and detailed study ever carried out in Latin America $^{(34)}$. The present article assesses the nutritional status of Indigenous women from 14 to 49 years of age in Brazil.

\section{Methods}

A stratified probability sample of the country's official geopolitical regions (North, Northeast, Central-West and
South/Southeast; the South and Southeast regions were joined due to their substantially smaller Indigenous populations) was obtained using multistage sampling based on a list of Indigenous villages provided in 2008 by the Brazilian National Health Foundation ${ }^{(34)}$. Of the list's 3995 villages located in federally recognised Indigenous Reserves, 1227 were excluded due to indications that they were vacated, deactivated or otherwise unstable (151 villages), or had $<31$ inhabitants (1076 villages), which was the minimum village size investigated.

Sample size was calculated for each region considering a prevalence of $50 \%$ for all disease outcomes, a relative error of $5 \%$ and a CI of $95 \%{ }^{(35)}$. Women aged $14-49$ years were considered adults and included in the analyses (see Coimbra et al. ${ }^{(34)}$ for a detailed sampling procedure). Interviews and clinical examinations were conducted in women's homes, in Portuguese, with local Indigenous translators when needed.

Body weight was measured to the nearest $100 \mathrm{~g}$ with a portable digital scale (Seca model 872) and with participants wearing minimal clothing and without footwear. Standing height was measured with an AlturaExata portable anthropometer and recorded to the nearest $0 \cdot 1 \mathrm{~cm}$. Anthropometric measurements were carried out by trained and standardised field researchers ${ }^{(34)}$.

In accordance with WHO guidelines, BMI of women $\geq 20$ years of age was classified as underweight $\left(<18.5 \mathrm{~kg} / \mathrm{m}^{2}\right)$, normal weight $\left(18.5-24.9 \mathrm{~kg} / \mathrm{m}^{2}\right)$, overweight $\left(25 \cdot 0-29.9 \mathrm{~kg} / \mathrm{m}^{2}\right)$ and obese $\left(\geq 30 \mathrm{~kg} / \mathrm{m}^{2}\right)^{(36)}$. For participants aged $14-19$ years, cut-off points proposed by de Onis ${ }^{(37)}$ were followed. Excess weight was calculated as the sum of overweight and obesity frequencies. Data for pregnant women and women with unreported pregnancy status were excluded from the analysis.

In the initial data analysis, the prevalence of excess weight and obesity was calculated according to independent variables (village, household and women's individual demographic, socioeconomic and reproductive characteristics).

Contextual village-level independent variables included geopolitical region, village food acquisition activities (hunting, fishing and collecting) and presence of a school meals programme.

Household-level variables included regular income (presence of income from salaries, pensions or social benefits), several composite socioeconomic indicators derived through principal component analyses (see below), number of household residents, access to indoor electricity, household food acquisition activities (horticulture and livestock, and purchasing), access to a staple food donation programme (cesta básica), a purchased foods index derived through principal component analyses (see below), type of cooking fuel and use of oils and fats for cooking.

A principal component analysis was used to create the following socioeconomic and living condition variables: (a) 
household goods index, based on the quantities of durable industrialised goods in each household (first component explained $19 \%$ of variance, eigenvalue 3.56); (b) housing conditions index, based on the type of flooring, walls, roofing, presence of electricity and fuel used for cooking (first component explained $48.0 \%$ of variance, eigenvalue 1.44 ); and (c) sanitation index, based on the primary defecation location, trash disposal destination, primary source of drinking water and availability of filtered water for drinking in the house (first component explained $56.5 \%$ of variance, eigenvalue 0 .63). Households received scores based on the sum of the contribution of each item multiplied by the quantity of each item before being classified according to terciles of the overall distribution, considering the four regions combined. In each case, the first tercile indicates a lower index score associated with fewer durable industrialised goods, less access to 'high-quality' housing materials and resources and lower-quality sanitation conditions.

A principal component analysis was also utilised to derive a household purchased foods acquisition index using fourteen food items: rice, corn, manioc, tubers (sweet potatoes and yams), beans, fruits, nuts, vegetables, milk, egg, chicken, beef, game and fish. Varimax rotation was used to improve component interpretation. Food items were considered representative of each component if they showed a loading $>0 \cdot 3$. The first component, which explained $23.3 \%$ of variance (eigenvalue $3 \cdot 26$ ), was dominated by predominantly purchased food items (rice, beans, milk, egg, chicken and beef), whereas the second and third components (not utilised in the analyses) were dominated by locally produced and acquired foods. As above, household purchased foods acquisition index scores were the sum of the contribution of each item multiplied by item quantity, classified according to terciles of the combined distribution.

Women's individual variables included age group, years of schooling and number of children ever born (parity).

Multivariate multilevel hierarchical analyses were conducted based on a theoretical model of two ranked blocks comprising (1) village and (2) household and individual characteristics. All estimates were made using xtme family commands and were corrected for the complex sampling design using Stata survey commands $(s v y)^{(38)}$. The association of each independent variable with the presence of excess weight and obesity was estimated using logistic regression, adjusting for region of residence. Independent variables with $P$-values $<0.20$ in this analysis were selected for further multivariate hierarchical analyses. Variables with at least one category with $P \leq 0.20$ for excess weight or obesity are indicated in Tables $1-3$.

Independent variables entered the multivariate analysis with their respective blocks in the theoretical hierarchical model, from distal block 1 to proximal block 2 . For the first block, selected village variables $(P<0 \cdot 20)$ were jointly included in the model, controlling for geopolitical region. A backward procedure was then used to progressively exclude variables, retaining only those with a significance level of $P<0.05$. These procedures were the same for the second block, which included household and individual variables. Therefore, in the final model, the OR and respective $95 \%$ CI were simultaneously adjusted for variables with $P<0.05$ in the same block of variables, those retained in the previous block, and geopolitical region. We also computed OR with $90 \%$ CI but found that results did not

Table 1 Prevalence and OR (from logistic regression) for excess weight and obesity of Indigenous women 14-49 years of age, according to region and village characteristics (First National Survey of Indigenous People's Health and Nutrition in Brazil, 2008-9)

\begin{tabular}{|c|c|c|c|c|c|c|c|c|}
\hline \multirow[b]{2}{*}{ Variable } & \multicolumn{4}{|c|}{ Excess weight ${ }^{*}$} & \multicolumn{4}{|c|}{ Obesity† } \\
\hline & $n$ & Prevalence (\%) & OR & $95 \% \mathrm{Cl}$ & $n$ & Prevalence (\%) & OR & $95 \% \mathrm{Cl}$ \\
\hline \multicolumn{9}{|l|}{ Region } \\
\hline North & 645 & 31.2 & 1.0 & reference & 125 & $6 \cdot 1$ & 1.0 & reference \\
\hline Central-West & 591 & $52 \cdot 8$ & 2.5 & $1.66,3.68$ & 192 & $17 \cdot 2$ & $3 \cdot 2$ & $1.58,6.37$ \\
\hline Northeast & 651 & $41 \cdot 3$ & 1.6 & $1.04,2.32$ & 213 & $13 . \overline{5}$ & 2.4 & $1 \cdot 21,4.74$ \\
\hline South/Southeast & 517 & $54 \cdot 7$ & $2 \cdot 7$ & $1.49,4.78$ & 212 & $22 \cdot 6$ & 4.5 & $1.95,10.17$ \\
\hline Brazil & 2404 & $46 \cdot 2$ & & & 742 & $15 \cdot 8$ & & \\
\hline \multicolumn{9}{|l|}{ Hunting } \\
\hline Yes & 1728 & $45 \cdot 8$ & 1.0 & reference & 519 & $15 \cdot 3$ & 1.0 & reference \\
\hline No & 676 & $47 \cdot 3$ & $1 \cdot 1$ & $0.68,1.63$ & 223 & $16 \cdot 8$ & $1 \cdot 1$ & $0.57,2.17$ \\
\hline \multicolumn{9}{|l|}{ Fishing } \\
\hline Yes & 2178 & $45 \cdot 6$ & $1 \cdot 0$ & reference & 648 & $15 \cdot 3$ & $1 \cdot 0$ & reference \\
\hline No & 226 & 53.5 & 1.4 & $0.96,1.96$ & 94 & 21.4 & 1.5 & $0.95,2.40$ \\
\hline \multicolumn{9}{|l|}{ Food collection } \\
\hline Yes & 1938 & $45 \cdot 0$ & 1.0 & reference & 564 & 15 & 1.0 & reference \\
\hline No & 466 & $51 \cdot 1$ & 1.3 & $0.95,1.82$ & 178 & $19 \cdot 3$ & 1.4 & $0.92,2.01$ \\
\hline \multicolumn{9}{|c|}{ School meals programme } \\
\hline Yes & 2047 & $47 \cdot 2$ & 1.0 & reference & 652 & $16 \cdot 5$ & $1 \cdot 0$ & reference \\
\hline No & 357 & 40.5 & 0.8 & $0.57,1.02$ & 90 & $11 \cdot 3$ & 0.6 & $0.43,0.95$ \\
\hline
\end{tabular}

${ }^{*} \mathrm{BMI} \geq 25 \mathrm{~kg} / \mathrm{m}^{2}$.

$\dagger B M I \geq 30 \mathrm{~kg} / \mathrm{m}^{2}$. 
Table 2 Prevalence and OR (from logistic regression) for excess weight and obesity of Indigenous women 14-49 years of age, according to household characteristics (First National Survey of Indigenous People's Health and Nutrition in Brazil, 2008-9)

\begin{tabular}{|c|c|c|c|c|c|c|c|c|}
\hline \multirow[b]{2}{*}{ Variable } & \multicolumn{4}{|c|}{ Excess weight ${ }^{*}$} & \multicolumn{4}{|c|}{ Obesity† } \\
\hline & $n$ & Prevalence (\%) & OR & $95 \% \mathrm{Cl}$ & $n$ & Prevalence (\%) & OR & $95 \% \mathrm{Cl}$ \\
\hline \multicolumn{9}{|l|}{ Regular income } \\
\hline Yes & 2087 & $47 \cdot 2$ & 1.3 & $1.02,1.67$ & 655 & $16 \cdot 2$ & 1.3 & $0.97,1.79$ \\
\hline No & 316 & 40.5 & 1.0 & reference & 87 & 12.9 & 1.0 & reference \\
\hline Household goods index & & & & $P \leq 0.20$ & & & & $P \leq 0.20$ \\
\hline 10 tercile (low) & 602 & 37.4 & 1.0 & reference & 130 & 9.9 & 1.0 & reference \\
\hline $2^{\circ}$ tercile & 803 & $46 \cdot 3$ & 1.4 & $1.22,1.71$ & 246 & $16 \cdot 4$ & 1.8 & $1.37,2.33$ \\
\hline $3^{\circ}$ tercile (high) & 999 & 52.5 & 1.9 & $1.52,2.25$ & 366 & 19.5 & $2 \cdot 2$ & $1.54,3.20$ \\
\hline \multicolumn{9}{|l|}{ Housing conditions index } \\
\hline $1^{\circ}$ tercile (low) & 684 & $40 \cdot 3$ & 1.0 & reference & 152 & 9.7 & 1.0 & reference \\
\hline 2o tercile & 773 & 48.7 & 1.4 & $0.99,2.00$ & 255 & 19.5 & $2 \cdot 3$ & $1.42,3.59$ \\
\hline 3 o tercile (high) & 938 & $49 \cdot 0$ & 1.4 & $1.13,1.79$ & 332 & $17 \cdot 6$ & $2 \cdot 0$ & $1.55,2.57$ \\
\hline \multicolumn{9}{|l|}{ Sanitation index } \\
\hline 1o tercile (low) & 938 & $42 \cdot 7$ & 1.0 & reference & 256 & $14 \cdot 1$ & 1.0 & reference \\
\hline $2 \circ$ tercile & 657 & $46 \cdot 7$ & $1 \cdot 2$ & $0.86,1.60$ & 201 & $15 \cdot 3$ & $1 \cdot 1$ & $0.70,1 \cdot 75$ \\
\hline $3^{\circ}$ tercile (high) & 794 & $50 \cdot 0$ & 1.3 & $0.99,1.80$ & 282 & $18 \cdot 3$ & 1.4 & $0.88,2 \cdot 12$ \\
\hline \multicolumn{9}{|c|}{ Number of household residents } \\
\hline $1-3$ & 337 & 44.6 & 1.0 & reference & 101 & 13.4 & 1.0 & reference \\
\hline $4-6$ & 1036 & 48.9 & 1.2 & $1.00,1.42$ & 351 & $17 \cdot 6$ & 1.4 & $1.06,1.78$ \\
\hline $7-9$ & 706 & $47 \cdot 2$ & 1.1 & $0.90,1.37$ & 199 & $15 \cdot 3$ & $1 \cdot 2$ & $0.89,1.53$ \\
\hline$\geq 10$ & 318 & 37.9 & 0.8 & $0.55,1.04$ & 88 & 13.6 & 1.0 & $0.62,1.65$ \\
\hline \multicolumn{9}{|l|}{ Access to indoor electricity } \\
\hline Yes, continuous & 1711 & $49 \cdot 2$ & 1.7 & $1 \cdot 30,2 \cdot 21$ & 601 & $18 \cdot 4$ & $2 \cdot 7$ & $1.85,4.04$ \\
\hline Yes, discontinuous & 294 & $41 \cdot 2$ & $1 \cdot 2$ & $0.74,2.03$ & 67 & $10 \cdot 2$ & 1.4 & $0.70,2.75$ \\
\hline No & 397 & $36 \cdot 4$ & 1.0 & reference & 74 & $7 \cdot \overline{6}$ & 1.0 & reference \\
\hline \multicolumn{9}{|l|}{ Horticulture and livestock } \\
\hline Yes & 2019 & $45 \cdot 9$ & 1.0 & reference & 623 & $15 \cdot 8$ & 1.0 & reference \\
\hline \multirow{2}{*}{\multicolumn{9}{|c|}{ Hunting and fishing }} \\
\hline & & & & & & & & \\
\hline Yes & 1425 & 42.5 & 1.0 & reference & 399 & $13 \cdot 6$ & 1.0 & reference \\
\hline No & 978 & $51 \cdot 3$ & 1.4 & $1 \cdot 12,1 \cdot 81$ & 343 & $18 \cdot 8$ & 1.5 & $1 \cdot 02,2 \cdot 13$ \\
\hline \multicolumn{9}{|l|}{ Food collection } \\
\hline Yes & 1603 & 43.4 & 1.0 & reference & 460 & $14 \cdot 0$ & 1.0 & reference \\
\hline No & 800 & $52 \cdot 0$ & 1.4 & $1.15,1.74$ & 282 & 19.5 & 1.5 & $1 \cdot 10,2 \cdot 01$ \\
\hline \multicolumn{9}{|l|}{ Food purchasing } \\
\hline Yes & 2333 & $46 \cdot 5$ & 1.4 & $0.84,2.27$ & 737 & $16 \cdot 2$ & $7 \cdot 7$ & $1.93,30.66$ \\
\hline No & 70 & 38.5 & 1.0 & reference & 5 & 2.4 & 1.0 & reference \\
\hline \multicolumn{9}{|c|}{ Access to staple foods donation programme } \\
\hline Yes & 1116 & $50 \cdot 8$ & 1.5 & $1.15,1.92$ & 381 & $18 \cdot 2$ & 1.5 & $1.05,2.07$ \\
\hline No & 1287 & $41 \cdot 0$ & 1.0 & reference & 361 & 13.1 & 1.0 & reference \\
\hline \multicolumn{9}{|c|}{ Purchased foods acquisition index } \\
\hline 10 tercile (low) & 754 & 44.3 & 1.0 & reference & 213 & 14.9 & 1.0 & reference \\
\hline $2^{\circ}$ tercile & 920 & 44.2 & 1.0 & $0.81,1.23$ & 269 & $14 \cdot 1$ & 0.9 & $0.75,1.17$ \\
\hline $3^{\circ}$ tercile (high) & 727 & $50 \cdot 3$ & 1.3 & $1.03,1.58$ & 260 & $18 \cdot 6$ & $1 \cdot 3$ & $1.03,1.64$ \\
\hline \multicolumn{9}{|l|}{ Type of cooking fuel } \\
\hline Propane & 727 & $51 \cdot 8$ & 1.4 & $1.1 \overline{2}, 1.67$ & 254 & $19 \cdot 0$ & 1.4 & $1 \cdot 10,1 \cdot 73$ \\
\hline Others (firewood, etc.) & 1676 & 44.0 & 1.0 & reference & 488 & 14.5 & 1.0 & reference \\
\hline \multicolumn{9}{|c|}{ Use of oils and fats for cooking } \\
\hline Yes & 808 & $51 \cdot 1$ & 1.4 & $0.97,1.94$ & 282 & $20 \cdot 0$ & 1.6 & $1.02,2.57$ \\
\hline No & 1510 & 43.2 & 1.0 & reference & 444 & 13.4 & 1.0 & reference \\
\hline
\end{tabular}

${ }^{*} \mathrm{BMl} \geq 25 \mathrm{~kg} / \mathrm{m}^{2}$

$\dagger \mathrm{BMI} \geq 30 \mathrm{~kg} / \mathrm{m}^{2}$

differ from those obtained using $95 \%$ CI. All analyses were conducted with Stata $14.0^{(38)}$.

The National Committee on Research Ethics (Comissão Nacional de Ética em Pesquisa - CONEP) and the National Indian Foundation (Fundação Nacional do Índio - FUNAI) approved the study. In each Indigenous community, the field team held meetings with leaders and other community members to present and explain study objectives and procedures. A free and informed collective consent form was signed by leaders and other community representatives of villages that decided to participate. All villages, households or guardians could decline to participate at any time.

\section{Results}

Of the total target sample of 6722 women aged between 14 and 49 years evaluated by the National Survey, twenty-one did not participate due to absence, three due to declination and six for other reasons. Of 6692 participating women, 653 
Table 3 Prevalence and OR (from logistic regression) for excess weight and obesity of Indigenous women 14-49 years of age, according to individual characteristics (First National Survey of Indigenous People's Health and Nutrition in Brazil, 2008-9)

\begin{tabular}{|c|c|c|c|c|c|c|c|c|}
\hline \multirow[b]{2}{*}{ Variable } & \multicolumn{4}{|c|}{ Excess weight* } & \multicolumn{4}{|c|}{ Obesity† } \\
\hline & $n$ & Prevalence (\%) & OR & $95 \% \mathrm{Cl}$ & $n$ & Prevalence (\%) & OR & $95 \% \mathrm{Cl}$ \\
\hline Age (years) & & & & $P \leq 0.20$ & & & & $P \leq 0.20$ \\
\hline $14-19$ & 355 & 28.5 & 1.0 & reference & 49 & $4 \cdot 1$ & 1.0 & reference \\
\hline $20-24$ & 395 & $37 \cdot 0$ & 1.5 & $1.25,1.73$ & 105 & $11 \cdot 6$ & $3 \cdot 1$ & $2.13,4.42$ \\
\hline $25-29$ & 469 & $52 \cdot 8$ & $2 \cdot 8$ & $2 \cdot 25,3.49$ & 148 & $17 \cdot 9$ & $5 \cdot 1$ & $3.44,7.54$ \\
\hline 30-34 & 435 & $59 \cdot 4$ & 3.7 & $2 \cdot 84,4.74$ & 153 & $24 \cdot 1$ & $7 \cdot 4$ & $5 \cdot 37,10 \cdot 23$ \\
\hline $35-39$ & 329 & 59.9 & 3.7 & $2 \cdot 84,4.95$ & 130 & $25 \cdot 6$ & $8 \cdot 1$ & $5 \cdot 34,12 \cdot 17$ \\
\hline $40-44$ & 241 & $61 \cdot 7$ & $4 \cdot 0$ & $3.00,5.41$ & 82 & $22 \cdot 8$ & 6.9 & $4.94,9.63$ \\
\hline $45-49$ & 180 & $60 \cdot 9$ & 3.9 & $3.06,4.99$ & 75 & $29 \cdot 0$ & $9 \cdot 6$ & $6 \cdot 36,14.44$ \\
\hline Years of schooling & & & & $P \leq 0.20$ & & & & $P \leq 0.20$ \\
\hline 0 & 373 & $51 \cdot 7$ & 1.7 & $1 \cdot 21,2.42$ & 118 & $19 \cdot 4$ & $1 \cdot 8$ & $1.02,3.01$ \\
\hline $1-4$ & 995 & $50 \cdot 0$ & 1.6 & $1.26,2.03$ & 337 & $18 \cdot 4$ & $1 \cdot 7$ & $1 \cdot 20,2 \cdot 26$ \\
\hline $5-9$ & 623 & 43.5 & $1 \cdot 2$ & $1.01,1.50$ & 165 & $12 \cdot 9$ & $1 \cdot 1$ & $0.79,1.47$ \\
\hline$\geq 10$ & 402 & 38.5 & 1.0 & reference & 119 & $12 \cdot 1$ & 1.0 & reference \\
\hline Parity & & & & $P \leq 0.20$ & & & & $P \leq 0.20$ \\
\hline 0 & 330 & $31 \cdot 2$ & 1.0 & reference & 56 & $5 \cdot 8$ & 1.0 & reference \\
\hline $1-2$ & 621 & $40 \cdot 2$ & 1.5 & $1.21,1.82$ & 186 & $12 \cdot 6$ & $2 \cdot 3$ & $1.60,3.37$ \\
\hline $3-4$ & 600 & $54 \cdot 1$ & $2 \cdot 6$ & $2.09,3.23$ & 211 & $20 \cdot 8$ & $4 \cdot 3$ & $2 \cdot 91,6 \cdot 20$ \\
\hline$\geq 5$ & 848 & $58 \cdot 3$ & $3 \cdot 1$ & $2.48,3.80$ & 2285 & 22.9 & $4 \cdot 8$ & $3.47,6.59$ \\
\hline
\end{tabular}

${ }^{*} \mathrm{BMI} \geq 25 \mathrm{~kg} / \mathrm{m}^{2}$.

$\dagger \mathrm{BMI} \geq 30 \mathrm{~kg} / \mathrm{m}^{2}$.

were not eligible for the present analyses due to pregnancy and 286 due to unknown pregnancy status. Of the 5753 remaining eligible women, thirty-nine were excluded due to missing anthropometric data. The evaluation of nutritional status was completed for 5714 women (99.3\% of eligible participants for this outcome).

BMI varied from 14.4 to $55.2 \mathrm{~kg} / \mathrm{m}^{2}$, with a median of $24.0 \mathrm{~kg} / \mathrm{m}^{2}$ (IQR 21.6-27.3). Comparing the geopolitical regions addressed in the study, the highest median was encountered in the South/Southeast $\left(25.3 \mathrm{~kg} / \mathrm{m}^{2}\right.$, IQR 22.0-29.3) and the lowest in the North, with a median of $23 \cdot 1 \mathrm{~kg} / \mathrm{m}^{2}$ (IQR $21 \cdot 2-25 \cdot 6$ ).

The overall prevalence of excess weight and obesity was, respectively, 46.2 and $15.8 \%$ (Table 1 ). The highest prevalence of excess weight was recorded in the South/ Southeast $(54.7 \%)$, followed by the Central-West $(52.8 \%)$, Northeast (41.3\%) and North (31.2\%) regions. The prevalence of obesity was distributed by region in the same order as described for excess weight: South/ Southeast (22.6\%), Central-West (17.2\%), Northeast (13.5\%) and North (6.1\%). The only contextual villagelevel variable associated with excess weight based on a bivariate analysis of OR was geopolitical region. The only village-level variables showing a statistically significant association with obesity based on OR and CI were region and presence of a school meals programme (Table 1).

Of household-level variables (Table 2), only the sanitation index and presence of horticulture and livestock food acquisition were not associated with excess weight or obesity based on OR. The number of household residents, food purchasing and use of oils and fats for cooking were only associated with obesity. The overall observed pattern is that higher socioeconomic indicators, market-integrated living conditions and more reliance on purchased foods were associated with excess weight and obesity.

Concerning women's individual descriptive analyses (Table 3), the risk of excess weight and obesity tended to increase with age, although the pattern was more consistent for excess weight. Women with more years of schooling presented lower rates of excess weight and obesity. For both outcomes, OR increased with parity.

The following variables remained in the final multilevel model for excess weight (95\% CI): geopolitical region, household good index, age group and years of schooling (Table 4). Except for schooling, the same set of variables was retained in the multivariate model for obesity, along with household food purchasing, housing conditions index and parity (Table 5). In both models, the Central-West and South/Southeast regions presented the highest OR. Women living in the Central-West, Northeast and South/ Southeast regions were nearly 4.30, 2.89 and 5.64 times more likely to be obese compared to those living in the North. The overall pattern observed in the multivariate analyses is that higher socioeconomic indicators, marketintegrated living conditions and less reliance on local food production, as well as increased age and parity were associated with excess weight and obesity.

\section{Discussion}

Recently published studies present important international and global comparative analyses of the health and nutrition of Indigenous peoples ${ }^{(13,19,39,40)}$. Nutrition transition is a principal focus of these investigations due to the growing relevance of obesity and comorbidities for the 
Table $4 \mathrm{OR}$ and $95 \% \mathrm{Cl}$ for variables retained in the multilevel statistical models for excess weight $\left(\mathrm{BMI} \geq 25 \mathrm{~kg} / \mathrm{m}^{2}\right)$ (First National Survey of Indigenous People's Health and Nutrition in Brazil, 2008-9)

\begin{tabular}{|c|c|c|c|c|c|c|}
\hline \multirow[b]{2}{*}{ Variable } & \multicolumn{2}{|c|}{ Geopolitical region } & \multicolumn{2}{|c|}{ Model $1^{*}$} & \multicolumn{2}{|c|}{ Model 2† } \\
\hline & OR & $95 \% \mathrm{Cl}$ & OR & $95 \% \mathrm{Cl}$ & OR & $95 \% \mathrm{Cl}$ \\
\hline \multicolumn{7}{|l|}{ Geopolitical region } \\
\hline North & 1.00 & reference & 1.00 & reference & 1.00 & reference \\
\hline Central-West & 2.75 & $1 \cdot 71,4 \cdot 40$ & 2.58 & $1.64,4.06$ & $3 \cdot 16$ & $1.85,5.40$ \\
\hline Northeast & 1.50 & $1.02,2.21$ & 1.25 & $0.85,1.81$ & 1.32 & $0.85,2.05$ \\
\hline South/Southeast & 2.95 & $1.93,4.51$ & 2.53 & $1.68,3.80$ & 3.09 & $1.90,5.02$ \\
\hline \multicolumn{7}{|c|}{ Household goods index } \\
\hline $1^{\circ}$ tercile (low) & & & 1.00 & reference & 1.00 & reference \\
\hline $2^{\circ}$ tercile & & & 1.40 & $1.19,1.66$ & 1.48 & $1.22,1.79$ \\
\hline $3^{\circ}$ tercile (high) & & & 1.72 & $1.43,2.06$ & 1.84 & $1.48,2.28$ \\
\hline \multicolumn{7}{|l|}{ Age group } \\
\hline $14-19$ & & & & & 1.00 & reference \\
\hline $20-24$ & & & & & 1.69 & $1.36,2.09$ \\
\hline $25-29$ & & & & & 3.63 & $2 \cdot 87,4.60$ \\
\hline $30-34$ & & & & & $5 \cdot 11$ & $3.94,6.63$ \\
\hline $35-39$ & & & & & 6.08 & $4.56,8.12$ \\
\hline $40-44$ & & & & & $6 \cdot 72$ & $4.85,9.31$ \\
\hline $45-49$ & & & & & $5 \cdot 62$ & $3.98,7.96$ \\
\hline \multicolumn{7}{|l|}{ Years of schooling } \\
\hline 0 & & & & & 1.00 & reference \\
\hline $1-4$ & & & & & 1.25 & $1.00,1.56$ \\
\hline $5-9$ & & & & & 1.24 & $0.96,1.60$ \\
\hline$\geq 10$ & & & & & 0.88 & $0.66,1 \cdot 18$ \\
\hline
\end{tabular}

*Model 1 includes village and household variables retained in the analysis, adjusted by region.

†Model 2 includes village, household and individual variables retained in the analysis, adjusted by region.

Table 5 OR and $95 \% \mathrm{Cl}$ for variables retained in the multilevel statistical models for obesity $\left(\mathrm{BMI} \geq 30 \mathrm{~kg} / \mathrm{m}^{2}\right)$ (First National Survey of Indigenous People's Health and Nutrition in Brazil, 2008-9)

\begin{tabular}{|c|c|c|c|c|c|c|}
\hline \multirow[b]{2}{*}{ Variable } & \multicolumn{2}{|c|}{ Geopolitical region } & \multicolumn{2}{|c|}{ Model $1^{*}$} & \multicolumn{2}{|c|}{ Model 2† } \\
\hline & OR & $95 \% \mathrm{Cl}$ & OR & $95 \% \mathrm{Cl}$ & OR & $95 \% \mathrm{Cl}$ \\
\hline \multicolumn{7}{|l|}{ Geopolitical region } \\
\hline North & 1.00 & Reference & 1.00 & reference & 1.00 & reference \\
\hline Central-West & $4 \cdot 30$ & $2 \cdot 25,8 \cdot 23$ & 3.80 & $2 \cdot 13,7.45$ & 4.96 & $2 \cdot 32,10 \cdot 61$ \\
\hline Northeast & 2.89 & $1.66,5.00$ & $2 \cdot 18$ & $1.26,3.79$ & $2 \cdot 29$ & $1 \cdot 19,4.42$ \\
\hline South/Southeast & 5.64 & $3.13,10 \cdot 15$ & $4 \cdot 23$ & $2.39,7.51$ & $5 \cdot 32$ & $2 \cdot 65,10 \cdot 67$ \\
\hline \multicolumn{7}{|c|}{ Household goods index } \\
\hline $1^{\circ}$ tercile (low) & & & 1.00 & reference & 1.00 & reference \\
\hline 2o tercile & & & 1.54 & $1 \cdot 18,2.01$ & 1.70 & $1 \cdot 24,2 \cdot 31$ \\
\hline $3^{\circ}$ tercile (high) & & & 1.98 & $1.49,2.64$ & $2 \cdot 16$ & $1.53,3.03$ \\
\hline \multicolumn{7}{|c|}{ Household food purchasing } \\
\hline Yes & & & $4 \cdot 28$ & $1.67,10.98$ & 4.91 & $1.74,13 \cdot 86$ \\
\hline No & & & 1.00 & reference & 1.00 & reference \\
\hline \multicolumn{7}{|c|}{ Housing conditions index } \\
\hline $1^{\circ}$ tercile (low) & & & 1.00 & reference & 1.00 & Reference \\
\hline $2^{\circ}$ tercile & & & 1.35 & $1.01,1.82$ & 1.35 & $0.96,1.92$ \\
\hline $3^{\circ}$ tercile (high) & & & 1.11 & $0.81,1.51$ & $1 \cdot 12$ & $0.78,1.60$ \\
\hline \multicolumn{7}{|l|}{ Age group } \\
\hline $14-19$ & & & & & 1.00 & reference \\
\hline $20-24$ & & & & & 2.49 & $1.61,3.86$ \\
\hline $25-29$ & & & & & $5 \cdot 10$ & $3 \cdot 16,8 \cdot 23$ \\
\hline $30-34$ & & & & & 7.99 & $4.73,13.52$ \\
\hline $35-39$ & & & & & $10 \cdot 72$ & $6.09,18.89$ \\
\hline $40-44$ & & & & & 9.07 & $4.99,16.49$ \\
\hline $45-49$ & & & & & 11.91 & $6 \cdot 38,22 \cdot 25$ \\
\hline \multicolumn{7}{|l|}{ Parity } \\
\hline 0 & & & & & 1.00 & reference \\
\hline $1-2$ & & & & & 1.49 & $0.99,2.23$ \\
\hline $3-4$ & & & & & 1.72 & $1 \cdot 10,2 \cdot 67$ \\
\hline$\geq 5$ & & & & & 1.42 & $0.89,2.27$ \\
\hline
\end{tabular}

*Model 1 includes village and household variables retained in the analysis, adjusted by region.

†Model 2 includes village, household and individual variables retained in the analysis, adjusted by region. 
determination of illness and death in Indigenous populations. Nevertheless, it is important to recall that in diverse world regions such as Latin America, food insecurity, child undernutrition and elevated burden of infectious and parasitic diseases persist in Indigenous peoples' epidemiological profiles, generally reaching much higher levels than those recorded for their respective benchmark national populations $^{(13,40-42)}$.

Based on a global comparative analysis of Indigenous peoples' health, obesity emerges as one of the most worrying health problems. It affects $50-70 \%$ of the Indigenous adult populations in countries such as the United States, Canada and New Zealand ${ }^{(43)}$, surpassing rates observed in the non-Indigenous populations in these countries. Transformations in diets, loss of territories and accelerated urbanisation are among the factors identified as connected to the accelerated nutrition transition observed in Indigenous populations in diverse world regions ${ }^{(44,45)}$.

Until recently, the nutritional and health situation of Indigenous peoples in Brazil was known only through specific village or community case studies due to the absence of nationwide surveys. Consequently, it was difficult to generalise about nutrition transition among the country's ethnically diverse Indigenous peoples ${ }^{(34)}$. The present National Survey, which is the largest health study of the Indigenous population in Brazil yet conducted based on a representative sample at national and regional levels, shows that the levels of excess weight in Indigenous women are similar to the national nutritional transition profiles $^{(46)}$. Whereas $46 \cdot 2$ and $15.8 \%$ of Indigenous women evaluated in the present study presented excess weight and obesity, respectively, these values were 48.0 and $16.9 \%$ for all adult Brazilian women based on a national study conducted in 2008-9 ${ }^{(46)}$. Comparing the results of nationally representative surveys since the 1970s, the prevalence of obesity among adult women generally has increased by 2.3 times over approximately four decades $(7.2 \%$ in $1974-5$ and $16.9 \%$ in $2008-9)^{(9,46)}$. There are no nationally representative data on the progression of excess weight and obesity through time for Brazil's Indigenous population. However, it is known from case studies conducted in specific communities that the onset and evolution of obesity is a relatively recent and accelerated process. This conclusion is deduced from the relative absence of studies highlighting excess weight and obesity in the health profile of Indigenous populations until the $1990 \mathrm{~s}^{(24,28-30)}$.

The National Survey also permits the first comparisons between Brazil's major geopolitical regions (North, CentralWest, Northeast and South/Southeast). Stratification of the occurrence of excess weight and obesity according to these four regions reveals a scenario of extremes of great epidemiological and socio-anthropological significance. Whereas obesity affected $22.6 \%$ of women in the South/Southeast, the prevalence observed in the North was almost four times less, at $6.1 \%$. Also, the South/Southeast and Central-West regions presented the highest frequencies of excess weight, with more than half of Indigenous women affected (54.7 and $52.8 \%$, respectively). In contrast, the prevalence of excess weight in the North was $31.2 \%$. These comparisons highlight important interregional differences in the nutritional profiles of Indigenous women in Brazil, such as between the North, dominated by Amazonia, and the South/Southeast, which includes the country's largest metropolitan regions. They also show that even in the North, where the lowest levels of excess weight and obesity were encountered, there is strong evidence of nutrition transition, as previously documented by local case studies ${ }^{(24,29)}$.

Similar geographical distributions among the Indigenous populations in Brazil have been described for other chronic diseases such as arterial hypertension and diabetes mellitus. In a previous paper presenting the findings of the National Survey, $13 \cdot 2 \%$ of Indigenous women nationwide were found to present hypertension, while this prevalence was just $3.6 \%$ in the North ${ }^{(34)}$. Compared to the North, hypertension prevalence was about three times higher in the Northeast and five times higher in the South/ Southeast and Central-West. Similarly, the nationwide prevalence of high blood glucose values, suggestive of diabetes mellitus, in women was $1.4 \%$, ranging from $0.5 \%$ in the North to $2 \cdot 1 \%$ in the South/Southeast ${ }^{(34)}$. Although the observed patterns of geographical contrasts are similar for hypertension, high blood glucose, excess weight and obesity, the scales are quite different. With excess weight and obesity showing much higher frequencies than hypertension and high blood glucose, it may be concluded that the nutritional pattern observed in Indigenous women nationwide reflects the nutrition transition trajectory documented in other Indigenous and nonIndigenous populations, whereby a widespread occurrence of obesity precedes the entrance of hypertension and diabetes.

Explanations of the expressively lower levels of excess weight and obesity in the North compared to other regions may involve relatively direct ecological and behavioural determinant factors, especially those related to food environments and physical activity. For example, the North stands out from all other regions for having much higher numbers of villages that reported acquiring food by hunting, fishing and collecting ${ }^{(34)}$. Less directly, the interregional contrasts documented by the National Survey are historically derived from the geography of Brazil's expanding demographic and economic frontiers. Exemplifying this process and its implications for contemporary Indigenous peoples is the distribution of federally recognised Indigenous lands, which occupy about $13 \%$ of the Brazilian territory. Of the country's 117067410 ha of Indigenous reserves, $98 \%$ by area is in the Amazon, which predominates in the North and the northern portion of the Central-West region. The remaining $2 \%$ are scattered throughout other regions in the country, with the smallest and most discontinuous lands concentrated in the southern and coastal regions that were the first to be colonised by 
European settlers. The Indigenous peoples living in the North often retained greater access to territories and traditional landscape resources as a result of more recent histories of contact and social integration, along with late-twentieth-century public policies that were more favourable to the recognition of Indigenous land rights and the preservation of larger Indigenous reserves. The National Survey finding that food acquisition by hunting, fishing and collecting is most prevalent in the North is likely related to the historical contrasts in the country's distribution of indigenous lands ${ }^{(34)}$. Consistent with these previously published findings and explanations, bivariate analyses in the present study found the highest frequencies of excess weight and obesity in the Northeast and South/ Southeast regions and in households that did not report consuming foods obtained by hunting, fishing and collecting.

In the growing academic production of explanatory models for nutrition transition in Indigenous populations in different parts of the world, dietary and lifestyle changes (e.g. physical inactivity) have been highlighted as important factors associated with increased levels of excess weight and obesity in adults ${ }^{(13,44,47)}$. Due to the diversity of local and regional sociohistorical contexts in different parts of the world, caution is warranted in attempting to advance general explanatory models for the environmental, political and economic factors associated with the nutrition transition observed in many Indigenous populations. Nevertheless, an emerging pattern among many Indigenous peoples, supported by ample case studies in diverse world regions, is that greater integration in market economies tends to be associated with increased prevalence of excess weight and chronic non-communicable diseases such as diabetes and hypertension ${ }^{(48,49)}$. The results of the multivariate statistical modelling presented here show associations that align closely with these explanatory models. In addition to excess weight and obesity differing according to geopolitical region, as discussed above, the results of multivariate models presented here also show that Indigenous women living in households that report purchasing foods are four times more likely to be obese. There was also an increased chance of obesity in women living in households with higher household goods index scores and higher housing conditions index (reflecting greater market insertion in terms of construction materials, access to electricity and cooking fuel).

The present results of the National Survey point to distinct patterns of associations between socioeconomic indicators and the occurrence of excess weight and obesity among Indigenous women. For example, whereas the household goods index and the existence of regular household income were positively associated in bivariate analyses with excess weight and obesity, more years of schooling was a protective factor for both outcomes. A similar scenario involving inverse relationships between income and schooling and the outcomes excess weight and obesity has also been described for the general adult population $^{(50)}$. In a comparative study on nutritional transition patterns in two regions of Brazil, Monteiro et al. ${ }^{(50)}$ observed that 'income tends to be a risk factor for obesity while education tends to be protective and that both gender and level of economic development are relevant modifiers of the influence exerted by these variables' (p. 885s). However, it is noteworthy that this difference was less accentuated in the multivariate models in the present study, which did not retain regular income as a significant variable, and in which only $\geq 10$ years of schooling acted as a protective factor.

Several notable independent variables were significantly associated with excess weight and/or obesity in bivariate analyses but lost significance in the multivariate multilevel analyses. At the village level, food acquisition activities (hunting, fishing and collecting) and presence of a school meals programme were not retained in either final model. At the household level, one of the two household food acquisition activities (horticulture/livestock) was not retained, nor the composite purchased foods index derived through the principal component analyses. Similarly, access to the staple foods donation programme and use of oils and fats for cooking lost significance in both models. The only household food access indicator retained in a final model was food acquisition by purchasing, an indicator serving to distinguish households that report not buying foods from those that report buying them. This pattern suggests that village-level food economic indicators were less sensitive for excess weight and obesity than household-level indicators. It also shows that indicators more closely related to market insertion (household goods index and purchasing food) were more directly determinant of obesity than those emphasising food economies and subsistence activities.

Although the National Survey represents an important advance in the study of Indigenous peoples' health in Brazil because it was representative at the national and regional levels, it should be noted that it was not designed to capture contrasts in nutritional profiles between specific Indigenous ethnic groups. As documented in the most recent Demographic Census conducted in Brazil in 2010, there are approximately 300 Indigenous ethnic groups in the country ${ }^{(51)}$, making Brazil one of the most ethnically diverse countries in the Americas and the world. This scale of national socio-diversity suggests the possibility of innumerable idiosyncratic profiles of engagement with Brazilian non-Indigenous society, each of which may involve distinct environmental or socioeconomic factors with the potential to influence nutritional transition, generally, and excess weight and obesity, specifically. In this sense, the findings presented here do not directly represent any singular Indigenous ethnic group in Brazil. Rather, the study was intended to capture broader frames of reference, the results of which suggest possible avenues of research for future medium (regional or ethnic group) to small-scale 
(community) surveys ${ }^{(34)}$. Nevertheless, the community studies conducted over the past two decades in different ethnic groups throughout the country's major geopolitical regions point to excess weight and obesity as generally prominent issues in the nutritional profile of adult Indigenous women. For example, women from numerous specific communities and ethnic groups presented prevalence of obesity $\geq 20 \%$, such as the Xavante, Terena, Guarani and Kaiowá in the Central-West ${ }^{(26,30,52)}$, the Xukuru in the Northeast ${ }^{(28)}$, the Suruí in the $\operatorname{North}^{(29)}$ and the Kaingang and Guaraní-Mbyá in the South/ Southwest ${ }^{(53,54)}$.

Several other potential limitations of the study should be noted. According to its original formulation, the National Survey focused on Indigenous women and children, not adult men, due to its primary emphasis on child and maternal health. The study therefore also excluded adolescents and elders of both sexes. Additionally, the list of villages used to select the sample population included only those located within federally recognised Indigenous reserves served by the Indigenous Healthcare Subsystem. Also, considering that 5714 (after exclusion) of 6692 participating women were analysed, the possibility of selection bias may be negligible. Furthermore, because data were collected from 2008 to 2009, they might not fully capture the present-day scenario. Finally, the cross-sectional nature of the study precludes assessing diachronic nutrition transition patterns or infer causality from associated risk factors.

In conclusion, this study indicates that higher socioeconomic indices, market-integrated living conditions and less reliance on local food production, as well as increased age and parity are associated with excess weight and obesity in adult indigenous women in Brazil. These findings from the National Survey have potentially significant implications from a public policy perspective for Indigenous peoples in Brazil. Frequencies of excess weight and obesity were found to be lower in regions (such as the North) where Indigenous populations have greater access to traditional territories. Access to land is an important condition for the continuation of traditional subsistence practices, potentially impacting not only dietary patterns but also physical activity. Another central issue is the need to consider the results in the context of public policies implemented by the Brazilian government aimed at improving food and nutrition security. Many of these policies have been based on governmental cash transfer programmes. For the general non-Indigenous Brazilian population, there is ample evidence that such initiatives are linked to the improvement of children's living conditions, as well as greater food security of beneficiary families ${ }^{(55)}$. However, in the case of Indigenous peoples, the few studies that have addressed these initiatives have not focused on their potential impacts on child or adult nutritional profiles ${ }^{(56)}$.

Finally, it is important to emphasise the need to carry out studies to monitor changes in the nutritional situation of the Indigenous population through time, particularly considering the rapid nutritional transition in progress. In Brazil, the challenge remains to produce reliable nationally representative statistics at regular intervals on the health conditions of ethnic minorities, including Indigenous peoples $^{(57)}$, who often live in environmentally, nutritionally and socioeconomically vulnerable conditions.

\section{Acknowledgements}

Acknowledgements: The authors are grateful for the support and assistance offered by Indigenous leaders and community members in all villages surveyed, as well as the staff at local National Indian Foundation (FUNAI) and National Health Foundation (FUNASA) offices. The administrative support provided by the Brazilian Public Health Association's (ABRASCO) staff greatly facilitated travel and financial logistics. Financial support: Financial support was provided by the Brazilian Ministry of Health and the World Bank through a grant provided to ABRASCO. The Wellcome Trust supported data analysis and manuscript preparation (grant 203486/Z/16/Z). Funders had no role in the design, analysis or writing of this article. Conflicts of interest: There are no conflicts of interest to declare. Authorship: C.E.A.C., B.L.H., R.V.S., A.M.C. and J.R.W. formulated the research concept and design. All authors were involved in data collection. A.A.F., A.M.C., F.G.T., R.V.S. and B.L.H. conducted statistical analyses. C.E.A.C., R.V.S., J.R.W. and F.G.T. drafted the manuscript. The final version submitted for publication was read and approved by all authors. Ethics of human subject participation: This study was conducted according to the guidelines laid down in the Declaration of Helsinki, and all procedures involving study participants were approved by the National Committee on Research Ethics (Comissão Nacional de Ética em Pesquisa CONEP) and the National Indian Foundation (Fundação Nacional do Índio - FUNAI). In each Indigenous community, the field team held meetings with leaders and other community members to present and explain study objectives and procedures. A free and informed collective consent form was signed by leaders and other community representatives of villages that decided to participate. All villages, households or guardians could decline to participate at any time.

\section{References}

1. NCD Risk Factor Collaboration (2016) Trends in adult bodymass index in 200 countries from 1975 to 2014: a pooled analysis of 1698 population-based measurement studies with $19 \cdot 2$ million participants. Lancet 387, 1377-1396.

2. Ng M, Fleming T, Robinson M et al. (2014) Global, regional, and national prevalence of overweight and obesity in children and adults during 1980-2013: a systematic analysis for the Global Burden of Disease Study 2013. Lancet 384, 766-781. 
3. Stevens GA, Singh GM, Lu Y et al. (2012) National, regional, and global trends in adult overweight and obesity prevalences. Popul Health Metr 10.

4. Hu FB (2008) Obesity and cardiovascular disease. In Obesity Epidemiology, pp. 174195 [FB Hu, editor]. Oxford and New York: Oxford University Press.

5. Calle EE \& Kaaks R (2004) Overweight, obesity and cancer: epidemiological evidence and proposed mechanisms. Nat Rev Cancer 4, 579-591.

6. Popkin BM, Adair LS \& Ng SW (2012) Global nutrition transition and the pandemic of obesity in developing countries. Nutr Rev 70, 3-21.

7. Kain J, Vio F \& Albala C (2003) Obesity trends and determinant factors in Latin America. Cad Saúde Pública 19(Suppl. 1), S77-S86.

8. Monteiro CA, Conde WL \& Popkin BM (2004) The burden of disease from undernutrition and overnutrition in countries undergoing rapid nutrition transition: a view from Brazil. Am J Public Health 94, 433-444.

9. Monteiro CA, Benicio MD, Conde WL et al. (2000) Shifting obesity trends in Brazil. Eur J Clin Nutr 54, 342.

10. Dumith SC (2009) Physical activity in Brazil: a systematic review. Cad Saúde Pública 25, S415-S426.

11. Hallal PC, Victora CG, Wells JCK et al. (2003) Physical inactivity: prevalence and Associated Variables in Brazilian Adults: Med Sci Sports Exerc 35, 1894-1900.

12. Mielke GI, Hallal PC, Malta DC et al. (2014) Time trends of physical activity and television viewing time in Brazil: 2006-2012. Int J Behav Nutr Phys Act 11, 101.

13. Anderson I, Robson B, Connolly $\mathrm{M}$ et al. (2016) Indigenous and tribal peoples' health (The Lancet-Lowitja Institute Global Collaboration): a population study. Lancet $\mathbf{3 8 8}$, 131-157.

14. Story M, Evans M, Fabsitz RR et al. (1999) The epidemic of obesity in American Indian communities and the need for childhood obesity-prevention programs. Am J Clin Nutr 69, $747 \mathrm{~S}-754 \mathrm{~S}$.

15. Bjerregaard P, Jørgensen ME \& The Greenland Population Study Group (2013) Prevalence of obesity among Inuit in Greenland and temporal trend by social position. Am J Hum Biol 25, 335-340.

16. Galloway T, Blackett H, Chatwood S et al. (2012) Obesity studies in the circumpolar Inuit: a scoping review. Int $J$ Circumpolar Health 71, 18698.

17. Gracey MS (2007) Nutrition-related disorders in Indigenous Australians: how things have changed. Med J Aust 186, $15-17$.

18. Hawley NL \& McGarvey ST (2015) Obesity and diabetes in Pacific Islanders: the current burden and the need for urgent action. Curr Diab Rep 15, 29.

19. Montenegro RA \& Stephens C (2006) Indigenous health in Latin America and the Caribbean. Lancet 367, 1859-1869.

20. Mc Donald A, Bradshaw RA, Fontes F et al. (2015) Prevalence of obesity in Panama: some risk factors and associated diseases. BMC Public Health 15, 1075.

21. Albala C, Vio F, Kain J et al. (2002) Nutrition transition in Chile: determinants and consequences. Public Health Nutr 5, 123-128.

22. Vieira-Filho JPB (1977) O diabetes mellitus e as glicemias de jejum dos índios Caripuna e Palikur [Diabetes mellitus and fasting glycemic levels among the Caripuna and Palikur Indians]. Rev Assoc Médica Bras 23, 175-178.

23. Fleming-Moran M \& Coimbra CEA Jr (1990) Blood pressure studies among Amazonian native populations: a review from an epidemiological perspective. Soc Sci Med 31, 593-601.

24. Santos RV \& Coimbra CEA Jr (1996) Socioeconomic differentiation and body morphology in the Suruí of Southwestern Amazonia. Curr Anthropol 37, 851-856.

25. Oliveira GF, Oliveira TRR, Ikejiri AT et al. (2014) Prevalence of hypertension and associated factors in an Indigenous
Community of Central Brazil: a population-based study. PLOS ONE 9 e86278.

26. Soares LP, Fabbro ALD, Silva AS et al. (2015) Prevalence of metabolic syndrome in the Brazilian Xavante indigenous population. Diabetol Metab Syndr 7, 105.

27. Dal Fabbro AL, Franco LJ, da Silva AS et al. (2014) High prevalence of type 2 diabetes mellitus in Xavante Indians from Mato Grosso, Brazil. Ethn Dis 24, 35-40.

28. Fávaro TR, Santos RV, Cunha GM et al. (2015) Obesidade e excesso de peso em adultos indígenas Xukuru do Ororubá, Pernambuco, Brasil: magnitude, fatores socioeconômicos e demográficos associados [Obesity and overweight in adult Xukuru of Ororubá Indians, Pernambuco State, Brazil: magnitude and associated socioeconomic and demographic factors]. Cad Saúde Pública 31, 1685-1697.

29. LourençO AEP, Santos RV, Orellana JDY et al. (2008) Nutrition transition in Amazonia: obesity and socioeconomic change in the Suruí Indians from Brazil. Am J Hum Biol 20, 564-571.

30. Welch JR, Ferreira AA, Santos RV et al. (2009) Nutrition transition, socioeconomic differentiation, and gender among adult Xavante Indians, Brazilian Amazon. Hum Ecol 37, 13-26.

31. Escobar AL, Coimbra CEA Jr, Welch JR et al. (2015) Diarrhea and health inequity among Indigenous children in Brazil: results from the First National Survey of Indigenous People's Health and Nutrition. BMC Public Health 15, 191.

32. Cardoso AM, Horta BL, Santos RV et al. (2015) Prevalence of pneumonia and associated factors among indigenous children in Brazil: results from the First National Survey of Indigenous People's Health and Nutrition. Int Health 7, 412-419.

33. Horta BL, Santos RV, Welch JR et al. (2013) Nutritional status of indigenous children: findings from the First National Survey of Indigenous People's Health and Nutrition in Brazil. Int J Equity Health 12, 23.

34. Coimbra CEA Jr, Santos RV, Welch JR et al. (2013) The First National Survey of Indigenous People's Health and Nutrition in Brazil: rationale, methodology, and overview of results. BMC Public Health 13, 52.

35. Lemeshow S (1990) Adequacy of Sample Size in Health Studies. Chichester; New York: Wiley and Liss .

36. World Health Organization (2000) Obesity: Preventing and Managing the Global Epidemic: Report of a WHO Consultation. Geneva: World Health Organization.

37. de Onis M (2007) Development of a WHO growth reference for school-aged children and adolescents. Bull World Health Organ 85, 660-667.

38. StataCorp (2015) Stata Statistical Software: Release 14. College Station, TX: StataCorp LP.

39. Godoy R, Reyes-García V, Gravlee CC et al. (2009) Moving beyond a Snapshot to Understand Changes in the WellBeing of Native Amazonians: Panel Evidence (2002-2006) from Bolivia. Curr Anthropol 50, 563-573.

40. Larrea C \& Freire W (2002) Social inequality and child malnutrition in four Andean countries. Rev Panam Salud Pública 11, 356-364.

41. Ferreira AA, Welch JR, Cunha GM et al. (2016) Physical growth curves of Indigenous Xavante children in Central Brazil: results from a longitudinal study (2009-2012). Ann Hum Biol 43, 293-303.

42. Hurtado AM, Lambourne CA, James P et al. (2005) Human rights, biomedical science, and infectious diseases among South American indigenous groups. Annu Rev Anthropol 34, 639-665.

43. Bramley D, Hebert P, Jackson RT et al. (2004) Indigenous disparities in disease-specific mortality, a cross-country comparison: New Zealand, Australia, Canada, and the United States. N Z J Med 117, 1-16. 
44. Kuhnlein HV, Receveur O, Soueida R et al. (2004) Arctic indigenous peoples experience the nutrition transition with changing dietary patterns and obesity. J Nutr 134, 1447-1453.

45. Damman S, Eide WB \& Kuhnlein HV (2008) Indigenous peoples' nutrition transition in a right to food perspective. Food Policy 33, 135-155.

46. Conde WL \& Monteiro CA (2014) Nutrition transition and double burden of undernutrition and excess of weight in Brazil. Am J Clin Nutr 100, 1617S-1622S.

47. Poltavski D, Holm J, Vogeltanz-Holm N et al. (2010) Assessing health-related quality of life in Northern Plains American Indians: prominence of physical activity as a health behavior. Am Indian Alsk Native Ment Health Res 17, 25-48.

48. Piperata BA, Spence JE, Da-Gloria P et al. (2011) The nutrition transition in Amazonia: rapid economic change and its impact on growth and development in Ribeirinhos. Am J Phys Anthropol 146, 1-13.

49. Godoy R, Reyes-García V, Byron E et al. (2005) The effect of market economies on the well-being of Indigenous peoples and on their use of renewable natural resources. Annu Rev Anthropol 34, 121-138.

50. Monteiro CA, Conde WL \& Popkin BM (2001) Independent effects of income and education on the risk of obesity in the Brazilian adult population. J Nutr 131, 881S-886S.

51. Instituto Brasileiro de Geografia e Estatística (IBGE) (2010) Censo Demográfico 2010: Características gerais dos indígenas [2010 Demographic Census: General characteristics of the Indigenous population]. Rio de Janeiro: IBGE.
52. Oliveira GF, Oliveira TRR, Ikejiri AT et al. (2015) Prevalence of obesity and overweight in an Indigenous population in Central Brazil: a population-based cross-sectional study. Obes Facts 8, 302-310.

53. Cardoso AM, Mattos IE \& Koifman RJ (2001) Prevalência de fatores de risco para doenças cardiovasculares na população Guaraní-Mbyá do Estado do Rio de Janeiro [Prevalence of risk factors for cardiovascular disease in the Guaraní-Mbyá population of the State of Rio de Janeiro]. Cad Saude Pública 17, 345-354.

54. Boaretto JD, Molena-Fernandes CA, Pimentel GG et al. (2015) Estado nutricional de indígenas Kaingang e Guarani no estado do Paraná, Brasil [The nutritional status of Kaingang and Guarani indigenous peoples in the State of Paraná, Brazill. Ciênc Saúde Coletiva 20, 2323-2328.

55. Martins APB, Canella DS, Baraldi LG et al. (2013) Cash transfer in Brazil and nutritional outcomes: a systematic review. Rev Saúde Pública 47, 1159-1171.

56. Verdum R (editor) (2016) Estudos Etnográficos Sobre o Programa Bolsa Família Entre Povos Indígenas. Relatório Final [Ethnographic Studies about the Bolsa Família Program emong Indigenous Peoples: Final report]. Brasília: Ministério do Desenvolvimento Social e Agrário.

57. Santos RV, Guimarães BN, Simoni AT et al. (2019) The identification of the Indigenous population in Brazil's official statistics, with an emphasis on demographic censuses. Stat J IAOS 35, 29-46. 